\title{
Aerosol Properties over Ranchi Measured from Aethalometer
}

\author{
Manoj Kumar, Kumari Lipi, S. Sureshbabu ${ }^{1}$, N. C. Mahanti \\ Centre of Excellence in Climatology, Department of Applied Mathematics, Ranchi, India \\ ${ }^{1}$ Space Physics Laboratory, Vikram Sarabhai Space Centre, Thiruvananthapuram, India \\ E-mail: msinha_09@rediffmail.com \\ Received April 21, 2011; revised May 27, 2011; accepted June 9, 2011
}

\begin{abstract}
Continuous and near-real-time measurements of the mass concentration of Aerosol Black Carbon (BC) were carried out $1^{\text {st }}$ to $31^{\text {st }}$ July 2010 of rainy season and compare with data of July-2010 to March-2011 using an Aethalometer (model AE-31 of Magee Scientific, USA). The principle of the Aethalometer is to measure the attenuation of a beam of light transmitted through a filter, while the filter is continuously collecting an aerosol sample. This measurement is made at successive regular intervals of a time base period has been the BC mass concentration is estimated by measuring the change in the transmittance of a quartz filter tape, on to which the particles impinge. The instrument was operated at a time base of $5 \mathrm{~min}$, round the clock with a flow rate of 4-liter $\min ^{-1}$, to study the impact of rainy season on black carbon concentrations over a typical urban environment namely Ranchi, India. BC concentrations were high during morning (0600 to $0900 \mathrm{~h}$ ) and evening hours (1900 to 2300 h) compared to afternoon hours. During early morning hours, high values of BC are attributed to the turbulence set-in by the solar heating which breaks the night-time stable layer and aerosols in the nocturnal residual layer are mixed up with those near the surface.
\end{abstract}

Keywords: Black Carbon (BC), Aethalometer, Aerosol

\section{Introduction}

For several decades optical properties of aerosols have been an important subject in atmospheric research. Angstrom (1929) [1] found an empirical relationship between the size of the aerosol particles and the wavelength dependence of the extinction coefficient. Since Volz (1959) [2] introduced the first handheld analogue instrument, the technology of ground based atmospheric aerosol measurements using sun photometry has changed substantially. The observations, so far have been limited to point measurements through balloons, flux towers etc.

Modern Aethalometer can automatically collect data continuously with greater accuracies. The measured sky spectral radiances can be used to obtain the different optical and size properties of the aerosols in the total atmospheric column (Twitty, 1975 [3]; Kaufman et al., 1994 [4]; Nakajima et al., 1996 [5] ). The principle is based on the dependence of the light scattering phase function on aerosol particle size and wavelength. The radiative effects of BC cannot be neglected as it is dominant light-absorbing component of atmospheric aerosols. Ac- curate information on $\mathrm{BC}$ is essential for the predictions of the radiative forcing caused by Black Carbon Aerosols. Relatively small changes in the BC input data can change the radiative forcing from positive to negative (Haywood and Shine, 1995 [6]).Several studies have shown that $\mathrm{BC}$ has typical lifetimes ranging from 1 week to 10 days in the absence of precipitation (Reddy and Venkataraman, 2000 [7]; Babu and Moorthy, 2001[8])

\section{Data Used}

Continuous and near-real-time measurements of the mass concentration of aerosol BC were carried out July 2010 using an Aethalometer; model AE-31 of Magee Scientific, USA .provided by Space Physics Laboratory, Vikram Sarabhai Space Centre Thiruvananathapuram. The AE-31 series performs optical analysis at seven different wavelengths from $370 \mathrm{~nm}$ to $950 \mathrm{~nm}$ and has found widespread application in studies of atmospheric optics, radiative transfer etc. The $\mathrm{BC}$ mass concentration estimated by measuring the change in the transmittance of a quartz filter tape on to which the particles impinge. The 
instrument was operated at a time base of $5 \mathrm{~min}$, round the clock with a flow rate of 4-liter $\min ^{-1}$, the instrument has been factory calibrated and errors in the measurements are $\sim \pm 2$.

The AE-31 series 'Spectrum' models of Aethalometer use an optical source assembly that incorporates seven different solid-state light sources. These sources are activated sequentially to illuminate the aerosol sample at seven discrete wavelengths each time base cycle. In this way, we determined the optical attenuation at seven points across the spectrum from ultraviolet to near infrared. The AE-31 series adds analysis in the near-ultraviolet at $370 \mathrm{~nm}$, which responds with great sensitivity to aromatic organic species that are found in tobacco smoke, wood fire smoke, and fresh diesel exhaust.

\section{Case Study}

In the present study, measurements of Black Carbon Aerosols was carried out during July to study the impact of rainy season on black carbon concentrations over a typical urban environment namely Ranchi, India. Diurnal variations $\mathrm{BC}$ suggest that the concentrations on rainy days reaches lowest value up to $\left(\sim 1591 \mathrm{ng} / \mathrm{m}^{3}\right)$ and highest value up to $\left(\sim 5850 \mathrm{ng} / \mathrm{m}^{3}\right)$ during morning (06:00 to 9:00 h) and evening hours (19:00 to 23:00 h) lowest value reaches up to $\left(\sim 717 \mathrm{ng} / \mathrm{m}^{3}\right)$ and highest value reaches upto ( $2730 \mathrm{ng} / \mathrm{m}^{3}$ ) were high compared to afternoon hours. During early morning hours, high values of BC are attributed to the turbulence set-in by the solar heating which breaks the night-time stable layer and aerosols in the nocturnal residual layer are mixed up with those near the surface. Low values of BC during afternoon hours are attributed to the dispersion of aerosols, due to increase in boundary layer height. Sensitivity studies of the accuracy of the inversion have shown $\sim \pm 2$ per cent errors in most situations for data. In order to screen out the effects of clouds, storm and clear sky weather, all the data shown were passed a $\sim \pm 2$ error self-consistency

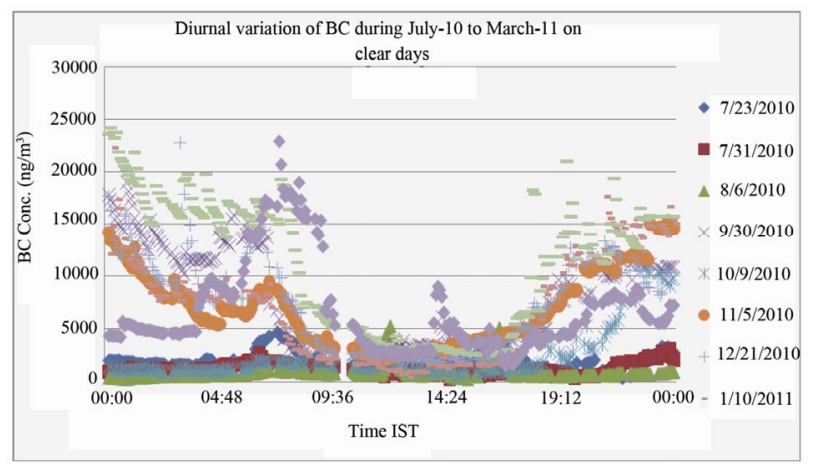

Figure 1. Diurnal variation of BC on very clear days from July 10 to March 11. testing criteria. Preliminary results of the data are presented.

Figure 1 shows the diurnal variation of black carbon aerosols at Ranchi during July-10 to March-11 on selected few days. The concentration of BC is measured in nano gram per cubic meter $\left(\mathrm{ng} / \mathrm{m}^{3}\right)$ using the Aethalometer. It reveals that $\mathrm{BC}$ concentration is high during morning and evening periods for all the days. The BC concentration shows the enhancement during 06:30 hr to 9:30 hr and a decreasing trends afterwards till noon. The BC concentration remains almost constant till late noon and start increasing again at around 18:00 hr till midnight. During nighttime BC concentration is high in comparison to daytime. During early morning, high values of BC have been attributed due to fumigation effect within the boundary layer, which brings in aerosols from the nocturnal residual layer. Shortly after sunrise, the concentration stars decreasing. The peak around 8:30 AM is due to morning traffic. Low values of BC during afternoon hours have been attributed to the dispersion of aerosols due to the turbulence caused by the solar heating which breaks the night time stable layer, and also due to increase in boundary layer height in addition to the low traffic density.

In Figure 2 Comparison of BC during clear and rainy days has been done. The peak value of BC during clear days reaches up to ( $\left.29154 \mathrm{ng} / \mathrm{m}^{3}\right)$ at 00:45 hrs, while during rainy days it reaches only up to $\left(\sim 5850 \mathrm{ng} / \mathrm{m}^{3}\right)$ at 06:10 hrs. This may be attributed due to washout of BC due to rain. BC significantly reduces after rainfall due to scavenging process and also due to reduction in the

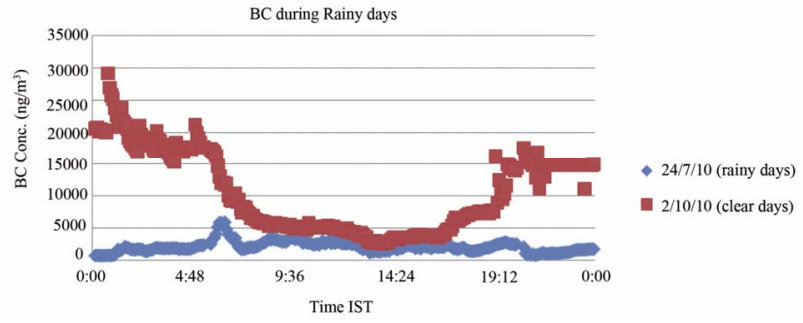

Figure 2. Diurnal variation of BC during rainy days.

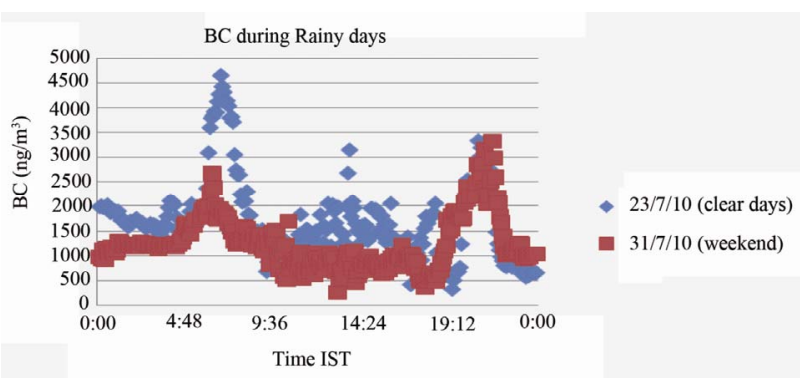

Figure 3. Diurnal variation of BC during weekend \& clear days. 


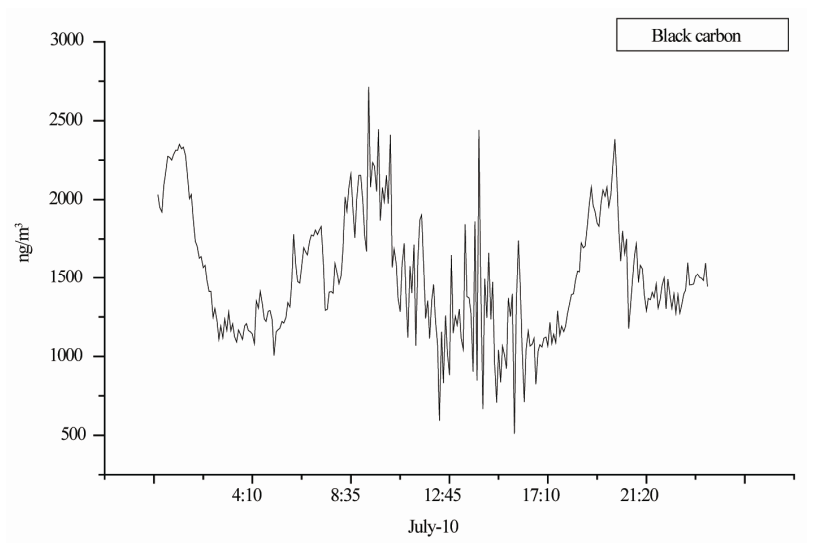

Figure 4. Diurnal variation of Aerosol concentration on rainy season of July on $880 \mathrm{~nm}$ black carbon concentration on hourly basis for July 10.

continental features conductive for aerosol generation by shifting the air mass (Latha and Badarinath [9], 2005). During daytime from 12:30 to 17:30 hrs, high BC values are observed during rainy days in comparison to clear days; which may be due to cloud cover during rainy days in comparison to clear days; which may be due to cloud cover during rainy days because the boundary layer is reduced during rainy days. Similarly, a comparison of BC concentration during clear day and weekend has been done (Figure 3), which shows that on clear day has higher BC concentration is observed in comparison to weekend, because at weekend vehicular pollution and other daily buses of school and official vehicle has closed. The peak value of BC during clear day reaches upto $\left(\sim 4658 \mathrm{ng} / \mathrm{m}^{3}\right)$ at 0600 to 0900 hours while during weekend it reaches only up to $(\sim 2683 \mathrm{ng} / \mathrm{m} 3)$ at 0600 to 0900 hrs.

In Figure 2, Comparison of BC during clear and rainy days has been done. The peak value of BC during clear days reaches up to $\left(\sim 29154 \mathrm{ng} / \mathrm{m}^{3}\right)$ at 00:45 hrs, while during rainy days it reaches only up to $\left(\sim 5850 \mathrm{ng} / \mathrm{m}^{3}\right)$ at 06:10 hrs. This may be attributed due to washout of BC due to rain. BC significantly reduces after rainfall due to scavenging process and also due to reduction in the continental features conductive for aerosol generation by shifting the air mass (Latha and Badarinath [9], 2005). During daytime from 12:30 to 17:30 hrs, high BC values are observed during rainy days in comparison to clear days; which may be due to cloud cover during rainy days in comparison to clear days; which may be due to cloud cover during rainy days because the boundary layer is reduced during rainy days. Similarly, a comparison of $\mathrm{BC}$ concentration during clear day and weekend has been done (Figure 3), which shows that on clear day has higher BC concentration is observed in comparison to weekend, because at weekend vehicular pollution and other daily buses of school and official vehicle has closed. The peak value of $\mathrm{BC}$ during clear day reaches up to $\left(\sim 4658 \mathrm{ng} / \mathrm{m}^{3}\right)$ at 06:00 to 09:00 hours while during weekend it reaches only up to $(\sim 2683 \mathrm{ng} / \mathrm{m} 3)$ at $06: 00$ to 09:00 hrs.

In Figure 4, the black carbon (BC) concentration during the month of July during rainy season (July-10), shows similar pattern of increasing trend at morning and evening and decreasing at afternoon time in comparison to rest of the selected days of different month shown in Figure 1.

\section{Conclusions}

Summarizing, the first study of aerosol optical properties and conc. distributions for the atmospheric column over Ranchi using Aethalometer have given great promise for future detailed studies of the origins of high pollution episodes in the region.

\section{References}

[1] A. Angstrom, "On the Atmospheric Transmission of Sun Radiation and on Dust in the Air," Geografiska Annaler, Vol. 11, 1929, pp. 156-166. doi:10.2307/519399

[2] F. E. Volz, "Photometer mit Selen-Photoelement zur spektralen Messung der Sonnenstrahlung und zur Bestimmung der Wellenlaengenabhaengigkeit de Dunsttruebung," Theoretical and Applied Climatology, Vol. 10, No. 1, 1959, pp. 100-131. doi:10.1007/BF02243122

[3] J. T. Twitty, "The Inversion of Aureole Measurements to Derive Aerosol Size Distributions," Journal of Atmospheric Science, Vol. 32, No. 3, 1975, pp. 584-591. doi:10.1175/1520-0469(1975)032<0584:TIOAMT>2.0.C $\underline{\mathrm{O} ; 2}$

[4] Y. J. Kaufman, A. Gitelson, A. Karnieli, et al., "Size Distribution and Scattering Phase Function of Aerosol Particles Retrieved From Sky Brightness Measurements," Journal of Geophysical Research, Vol. 99, No. D5, 1994, pp. 10341-10345. doi:10.1029/94JD00229

[5] T. Nakajima, G. Tonna, R. Rao, et al., "Use of Sky Brightness Measurements from Ground for Remote Sensing of Particulate Polydispersions,” Applied Optics, Vol. 35, No. 15, 1996, pp. 2672-2686. doi:10.1364/AO.35.002672

[6] E. J. Highwood and R. P. Kinnersley, "When Smoke Gets in Our Eyes: The Multiple Impacts of Atmospheric Black Carbon on Climate, Air Quality and Health,” Environment International, Vol. 32, No. 4, 2006, pp. 560-566. doi:10.1016/j.envint.2005.12.003

[7] M. S. Reddy and C. Venkataraman, “Atmospheric Optical and Radiative Effects of Anthropogenic Aerosol Constituents from India,” Atmospheric Environment, Vol. 34, No. 26, 2000, pp. 4511-4523. doi:10.1016/S1352-2310(00)00105-9

[8] S. S. Babu and K. K. Moorthy, “Anthropogenic Impact 
on Aerosol Black Carbon Mass Concentration at a Tropical Coastal Station: A Case Study,” Earth Sciences, Vol. 81, No. 9, 2001, pp. 1208-1214.

[9] K. M. Latha, K. V. S. Badrinath, "Seasonal Variation of
Black Carbon Aerosols and Total Aerosol Mass Concentrations over Urban Environment in India,” Atmospheric Environment, Vol. 39, No. 22, 2005, pp. 4129-4141. doi:10.1016/j.atmosenv.2005.04.004 